\title{
Ethics of resource allocation to congenital heart surgery in variable-resource contexts
}

\author{
Kathleen N. Fenton ${ }^{1,2}$ \\ ${ }^{1}$ Division of Cardiovascular Sciences, National Heart, Lung, and Blood Institute, Bethesda, Maryland, USA; ${ }^{2}$ Department of Bioethics, Clinical \\ Center, National Institutes of Health, Bethesda, Maryland, USA \\ Correspondence to: Kathleen N. Fenton, MD, MS. Division of Cardiovascular Sciences, National Heart, Lung, and Blood Institute; National Institutes \\ of Health, One Rockledge Centre, 6705 Rockledge Drive, Room 306-G, Bethesda, MD 20817, USA. Email: Kathleen.Fenton@nih.gov.
}

\begin{abstract}
The vast majority of the estimated 1.1-1.7 million infants born every year with congenital heart disease (CHD) requiring intervention live in places where this treatment is not readily available. The longterm solution is to train cardiologists and surgeons and develop cardiac care centers, but there has been some debate about whether or not this is the right thing to do in low resource environments. Consideration of this dilemma using different ethical systems helps to outline where and when it is appropriate to dedicate scarce resources to what may seem a costly endeavor. Beginning with the principlist approach to bioethics (which focuses on the four principles of beneficence, non-maleficence, respect for persons, and justice) gives an initial framework of the problem: program establishment can be encouraged only when conditions are adequate for the proposed level of care, and must be done with a plan to provide the care in an equitable manner. Through the lens of public health ethics, the focus turns to distributive justice and utility: expenditures should be allocated in a manner that benefits the population as a whole. Consequentialist ethics, incorporating evidence from cost effectiveness analysis, leads to the conclusion that providing congenital heart surgery is a good use of resources in many emerging economies.
\end{abstract}

Keywords: Surgery; congenital heart disease (CHD); global health; ethics

Received: 20 June 2021; Accepted: 06 December 2021; Published: 30 September 2022.

doi: $10.21037 /$ asj-21-51

View this article at: https://dx.doi.org/10.21037/asj-21-51

\section{Background}

Approximately 140 million babies are born each year worldwide, and this number is expected to remain relatively constant in the coming years (1). Congenital heart disease (CHD), not including bicuspid aortic valve presenting in adulthood) occurs in 8-12 of every 1,000 live births (2), meaning that between 1.1 and 1.7 million children are born annually who need treatment or intervention for CHD. More than 250,000 deaths were caused by CHD in 2017, and there are approximately 12 million people globally living with CHD (3). Worse yet, most of them live in parts of the world where access to advanced cardiac care, including diagnosis, medical treatment, intervention and surgery, is not widely available. This may seem like a hopeless situation; in fact, arguments have been made that the ideal solution to reduce the mortality, morbidity and cost of CHD worldwide is to decrease the total number of children born: to eliminate suffering by eliminating the sufferers (2). Nevertheless, the survival of infants and children born with CHD has improved dramatically in many parts of the world (3). This has worsened global disparities in the short term: recent best-estimates of mortality from CHD remain near $20 \%$ in much of the world, but are now only $4-7 \%$ where care is readily available (4). Furthermore, both the incidence of CHD and its mortality rate in lowand middle-income countries (LMICs) are thought to be underreported due to lack of access to basic medical care and diagnostic capabilities (4), so the inequities are likely far worse (4). The disproportionate improvement is thus both a "call to arms", of sorts, and a reason to hope to bring this needed treatment to all children. Yet, how can we know 
whether heart surgery can be done safely and with good results in a new setting? Can we really justify the allocation of scarce resources to the treatment of children with CHD? Is heart surgery too expensive for most LMICs to afford? Should we really be encouraging LMICs to try to build heart surgery programs for children?

These questions of what we "should" do, or what "ought" to be done, are ethical ones. We can approach the ethical consideration of allocating scarce resources to cardiac program development in LMICs from different perspectives: those of standard biomedical (principlist) ethics, of public health ethics, and of consequentialist ethics incorporating cost-effectiveness data.

\section{Consideration of ethical principles}

Clinicians and clinical ethicists often begin to evaluate ethical dilemmas by considering them according to the principlist system, using the four commonly-cited ethical principles of autonomy (or, more generally, respect for persons), beneficence, non-maleficence and justice. These principles are intended to transcend cultures and religions, to be essentially foundational and (almost) universal (5). What actually constitutes beneficence or justice, and exactly who is a "person" deserving of respect, may, of course, be difficult points of contention and may very much reflect someone's individual background and perspective. The four principles are generally considered to have equal weights and, as such, are often best applied to identify and outline the nature of any given ethical dilemma. It can be difficult to use them to completely resolve a controversial issue.

The principle of autonomy requires that individuals who are able to do so be allowed and encouraged to make decisions regarding what happens to them. It is this principle that forms the basis for the requirement to obtain informed consent, for example for medical treatments or research participation. In pediatric cardiology and cardiac surgery, allowing parents or guardians to make decisions on behalf of their children is the most common manifestation of respect for persons. However, since it is the child who is the person respected, it is sometimes imperative that the health care provider, acting as fiduciary for the child, step in to protect the child's best interest. This principle does not apply directly to countries or populations of people, but can be considered by extension, in the sense that community or national leaders should be allowed to make decisions and set priorities that reflect the values and preferences of their constituents. To not do so would clearly reflect lack of respect for persons. We will return to this idea in the discussion of public health ethics.

The apparently mirrored principles of beneficence and non-maleficence can, at first, seem like two sides of the same coin, but upon further reflection it becomes clear that they may often be used to evaluate different things. When considering development of pediatric heart surgery programs, it is clear that we are (all) coming, hopefully, from the perspective of beneficence: we want to do a good thing. Children with CHD are in need of help; making a (correct) diagnosis and providing the necessary medical and surgical care are good things to do. Establishment of programs benefits not only the patients themselves, but also their families, their health care teams, and even other patients who are able to take advantage of the improved level of care they receive because of the increased experience of the providers and the added resources.

What about non-maleficence? Probably no one would put the necessary effort into pediatric heart surgery program development with the intention of doing harm. However, harm can be done. Perhaps most obviously: heart surgery can only be safely done in places where certain conditions are met: there need to be (reasonably) reliable sources of oxygen, power and water, there must be the capability to do the necessary laboratory and radiological examinations (including echocardiograms), and there must be a blood banking system. For all but the simplest surgical cases, ventilators and intensive care unit (ICU) monitors (and ICU nurses!) are also needed. Certain complex operations require additional specialized resources (and staff); many locations don't (and won't, in the short-term future) have the resources, for example, to do heart transplants or palliative management of complex single ventricle defects. Attempts to perform interventions, no matter how urgent or "necessary" they seem to be, without the required resources (including human resources and experience), indeed often cause harm, measured not only in financial costs but, more importantly, in suffering to the child, family and staff as well as, at least sometimes, in lost opportunities for other patients. It is therefore important to take a step back and carefully consider whether or not something should be done, whether it is an individual procedure or a "next step" in program development.

The principle of justice perhaps gets at the crux of the situation we want to discuss. Justice refers to the idea of giving each person what is "due", and encompasses concepts of equity and fairness. Necessary and desired care should be 
made available, when possible, to those who wish to have it, without regard for considerations such as race, sex/gender, religion, national or cultural origin. Ideally it should also not be affected by ability to pay. This brings up two obvious questions. First: how do we define "necessary," and who defines it? (Is it "necessary" only if life is in danger, or do quality of life and/or the ability to work also matter? Does the "chance of success" of the proposed treatment enter into the equation?) Second, and perhaps more difficult question, relates to the fact that one person's rights are mirrored by another's duties. If we argue that something "should" be provided, exactly upon whom does the duty to provide it fall? These are questions that make application of the basic principle of justice more complex than it might initially appear, even when discussing individual patients. At the population level, we also need to bring in the concept of distributive justice; this is true whether or not resources are particularly limited. Distributive justice refers to the fair allocation of both benefits and burdens across individuals and groups in a given population. There are many different frameworks that can be used, and a detailed discussion is beyond the scope of this short review. What they share in common is the idea of "providing moral guidance for the political processes and structures that affect the distribution of benefits and burdens in society (6)." Although there are obvious differences between health care systems in wealthy and emerging economies, the questions that arise relate to distributive justice are strikingly similar. It seems easy to say that resources should be taken from the "rich" and given to the "poor", until we try to define rich and poor. It can also be difficult to delineate the population in question, to answer the proverbial question: "but who is my neighbor?" Am I really responsible to help anyone, anywhere in the world?

\section{Population health ethics}

Our reflection on the principle of justice, and specifically of distributive justice, leads directly into a different way to consider the ethics of cardiac surgical program development: through the lens of public health ethics. Public health experts generally focus most of their attention on the population as a whole; interventions are promoted that are shown to improve health at the level of the population (often measured in incidence or prevalence of a given disease) (7); examples include putting iodine in table salt or taxing cigarettes and sugary beverages. Population health is defined as "the health outcomes of a group of individuals, including the distribution of such outcomes within the group (8)." Decisions that are made to benefit the population as a whole, or that benefit the theoretical "average" person, may not be the best decisions for any individual (9). Although public health often focuses on disease prevention, it also includes diagnosis and treatment of existing disease (10). Whereas medical care is centered on the patient-provider relationship, public health involves interaction with multiple stakeholders including government officials, private and non-profit organizations, payors, and professionals from many disciplines, and is directed at the health of the population rather than that of the individual (10). Heart surgery program development, then, is an activity that also concerns public health! Providers of care for children with CHD have a primary focus on the care of their patients; this can rightly include advocating on their behalf before public health authorities and legislators.

The "principles" of public health ethics are not as well defined as those of bioethics, and may be more sensitive to culture (10). However, there are some similarities. Expanding the two principles of beneficence and nonmaleficence, public health also requires that the balance of benefits over harms (and costs) is maximized; this is sometimes called utility (10). In addition to justice at the individual level, public health ethics includes both distributive justice (as introduced above), as well as procedural justice (for example, appropriate participation of stakeholders in decision making) (10). Finally, from the concept of respect for persons, public health ethics concerns not only autonomy (individual decision-making), but also privacy, confidentiality, transparency and honoring commitments (10).

A discussion of public health ethics can also take into consideration the "Triple Aim" framework initially developed by the Institute for Healthcare Improvement (11) and adopted by the U.S. Agency for Healthcare Research and Quality (12). The three individual "aims" in this framework are designed to "optimiz(e) health system performance" by considering all stakeholders: patients as individuals ("improving the patient experience of care"), society ("improving the health of populations"), and payors ("reducing the per capita cost").

These principles of public health ethics are put into practice when consideration is given to beginning or expanding a congenital heart surgery program in a new country or region. Open, transparent discussions must be held with all stakeholders, including health care providers, hospital administrators, public health and government 
officials, representatives from funding organizations (insurance companies, nonprofits, and any others), and ideally patient or family groups. Decisions should reflect long-term plans, possibilities and goals and should be in accordance with community values and aligned with how other, similar health care priorities are set so that children with CHD can be treated in a way that is similar to patients with similar medical problems, and so that all children with CHD will have access to the treatment (10). Should this not be a possible or likely outcome, program establishment might be reconsidered.

\section{Consequentialist ethics}

We have already seen that public health ethics incorporates the concept of utility: decisions at the population level are, or should be, made taking into consideration, among other factors, the idea of maximizing benefits and minimizing costs. Here "costs" refers primarily to losses such as suffering, disability and death, not only financial cost (which includes lost productivity). Our ethical analysis of the promotion of pediatric cardiac care in emerging economies can be expanded in this way: by looking at costs and benefits, but now from the perspective of an ethicist. This partly expands on the bioethical principles of nonmaleficence and justice (13), and follows from the inclusion of the concept of utility in public health ethics.

In consequentialist ethical systems, the "rightness" or "wrongness" of an action is determined not by the act itself, but rather by its outcome or predicted outcome. Good actions are those that produce (or usually produce or are expected to produce) good outcomes. In order to decide whether or not establishing a heart surgery program for children is a "good" thing to do, a consequentialist would want to know how much good will be done, and how much it will cost. "Good" that will be done includes lives (or years of life) saved, but also quality of life; "cost" includes, in the first place lives (or years of life) lost, but also years lived with disability. Financial costs, on both sides of the costeffectiveness equation, are considered in relation to these patient-centered outcomes, and ideally should incorporate things like lost (or gained) productivity and wages in addition to the costs of the medical care itself. The use of cost effectiveness analysis can inform the consequentialist by providing information about the utility of congenital heart surgery in comparison to other alternative investments in health care.

While the earliest efforts in cost effectiveness analysis compared the costs of various interventions only to average years of life saved by their use, current systems incorporate various "losses" due to health problems into measures such as disability-adjusted life years (DALYs) or qualityadjusted life years (QALYs) (14). How these measurements are calculated is both complicated and controversial (14). For example, in the case of CHD, it requires giving a numerical score to a child with a ventricular septal defect and heart failure who lives with severe disability until early adolescence and then dies, and comparing this single number to that calculated for a child with a single ventricle who dies as an infant but with (arguably) less suffering. This may seem complicated enough, until we try to compare one of these children, instead, to a child who loses a leg in an accident, or to a young mother in the prime of life who gets cancer. The equation on the cost side is equally complicated: it must include not only the (financial) costs of the intervention itself, but also lost wages (over time) for the patient and sometimes the caregiver. In the discussion of program development, start-up costs must also be taken into consideration, but where surgery is not available, the costs of repeated clinic visits and hospitalizations should not be overlooked and may be substantial. Once the cost is calculated per chosen unit of improvement, this can be compared to costs for other interventions directed at prevention or treatment of a completely different health problem, in order to determine which intervention has greater utility.

CHD accounts for more than one third of hospitalizations and more than half of hospital costs for all birth defects (15). Going into the cost effectiveness equation, then, are both a high burden of disease and high cost of its management. In limited-resource settings, where few patients have health insurance, CHD causes significant financial burden to the child's family (16). The calculation of cost effectiveness of cardiac surgery is becoming increasingly common, and its methodology has been recently reviewed (17). Since most of this work has been done in wealthier environments (and largely in adult cardiac surgery for acquired heart disease), the actual values obtained have limited applicability to consideration of pediatric cardiac program development in emerging economies. The cost effectiveness of surgery for CHD in the context of humanitarian interventions has been found to be quite high (18), approaching that of other, more commonly-provided interventions. These calculations, while not providing a justification per se for the establishment of heart surgery programs in every location, certainly refute the argument that the intervention is too 
expensive and should generally be avoided, and form a basis for concluding that resources can reasonably be invested in pediatric heart surgery in many environments where it does not currently exist (13).

It is important to avoid equating cost effectiveness analysis or calculations of "utility" with consequentialist ethics. The broader question of whether or not heart surgery program development is "good" must take into consideration questions that cannot readily be measured and reduced to mathematical calculations, including those of equity and of caring for those in greatest need.

\section{Conclusions}

While advances in diagnosis, medical and surgical treatment for CHD have led to impressive improvements in outcomes in wealthy nations, most of the world's children are born in places where the necessary care is lacking. Global outcome inequities have thus gotten worse rather than better. Efforts to address these inequities by training providers and working to establish sustainable programs for the care of children with CHD have sometimes been criticized as being too resource-intensive, but a careful ethical analysis indicates that the dedication of resources to such program development can and should be encouraged in the great majority of environments. Surgery and complex cardiac care should be provided in accordance with the bioethical principles of beneficence and non-maleficence (that is, at a level of complexity where good outcomes can be anticipated based on the resources available, including provider experience). Opportunities for treatment should be equally available to all in need (principle of justice). Engagement with all stakeholders is crucial, and goals for program development should be aligned with community values and priorities, in keeping with public health ethics. Incorporation of the growing amount of information generated by robust cost-effectiveness analysis can help us better allocate scarce resources in a manner that is just, so that we make long-term progress toward the goal of improving the outcomes of children with CHD and reducing global health inequities. The level of responsibility that each of us has to contribute to this effort may be the topic of future discussion.

\section{Acknowledgments}

Funding: None.

\section{Footnote}

Provenance and Peer Review: This article was commissioned by the Guest Editors (Dominique Vervoort and Marcelo Cardarelli) for the series "Addressing Global Disparities in Pediatric and Congenital Cardiac Care" published in $A M E$ Surgical fournal. The article has undergone external peer review.

Peer Review File: Available at https://asj.amegroups.com/ article/view/10.21037/asj-21-51/prf

Conflicts of Interest: The author has completed the ICMJE uniform disclosure form (available at https://asj.amegroups. com/article/view/10.21037/asj-21-51/coif). The series "Addressing Global Disparities in Pediatric and Congenital Cardiac Care" was commissioned by the editorial office without any funding or sponsorship. KNF is an employee of the National Heart, Lung, and Blood Institute (NHLBI), National Institutes of Health (NIH). The author has no other conflicts of interest to declare.

Disclaimer: The views expressed in this article are those of the author and do not necessarily represent the views of the National Heart, Lung, and Blood Institute, the National Institutes of Health, or the United States Department of Health and Human Services.

Ethical Statement: The author is accountable for all aspects of the work in ensuring that questions related to the accuracy or integrity of any part of the work are appropriately investigated and resolved.

Open Access Statement: This is an Open Access article distributed in accordance with the Creative Commons Attribution-NonCommercial-NoDerivs 4.0 International License (CC BY-NC-ND 4.0), which permits the noncommercial replication and distribution of the article with the strict proviso that no changes or edits are made and the original work is properly cited (including links to both the formal publication through the relevant DOI and the license). See: https://creativecommons.org/licenses/by-nc-nd/4.0/.

\section{References}

1. Ritchie, Hannah. How many people die and how many are born each year? Our World in Data. Accessed June 
14, 2021. Available online: https://ourworldindata.org/ births-and-deaths\#: :text=Population \% 20projections $\% 20$ show\%20that\%20the,year\%20over\%20the\%20 coming\%20decades

2. Hoffman JIe. The global burden of congenital heart disease. Cardiovasc J Afr 2013;24:141-5.

3. GBD 2017 Congenital Heart Disease Collaborators. Global, regional, and national burden of congenital heart disease, 1990-2017: a systematic analysis for the Global Burden of Disease Study 2017. Lancet Child Adolesc Health 2020;4:185-200.

4. Bernier PL, Stefanescu A, Samoukovic G, et al. The challenge of congenital heart disease worldwide: epidemiologic and demographic facts. Semin Thorac Cardiovasc Surg Pediatr Card Surg Annu 2010;13:26-34.

5. Beauchamp T, Childress J. Principles of Biomedical Ethics, 6th edition. NY, USA: Oxford University Press, 2008.

6. Lamont J, Favor C. "Distributive Justice." The Stanford Encyclopedia of Philosophy (Winter 2017 Edition), Edward N. Zalta (ed.). Available online: https://plato. stanford.edu/archives/win2017/entries/justice-distributive/

7. Gostins LO, Wiley LF. Public health ethics and law. Hastings Center Bioethics Briefings, 2015. Available online: https://www.thehastingscenter.org/briefingbook/ public-health/. Accessed June 14, 2021.

8. Institute of Medicine. Vital signs: core metrics for health and health care progress. Washington, DC: The National Academies Press, 2015.

9. DeCamp M, Pomerantz D, Cotts K, et al. Ethical Issues in the Design and Implementation of Population Health Programs. J Gen Intern Med 2018;33:370-5.

doi: $10.21037 /$ asj-21-51

Cite this article as: Fenton KN. Ethics of resource allocation to congenital heart surgery in variable-resource contexts. AME Surg J 2022;2:22.
10. Childress JF, Faden RR, Gaare RD, et al. Public health ethics: mapping the terrain. J Law Med Ethics 2002;30:170-8.

11. Institute for Healthcare Improvement. The IHI Triple Aim. Available online: http://www.ihi.org/Engage/ Initiatives/TripleAim/Pages/default.aspx

12. Agency for Healthcare Research and Quality. About the National Quality Strategy. Available online: https://www. ahrq.gov/workingforquality/about/index.html\#aims

13. Fenton KN, Cardarelli M, Molloy F, et al. Ethics in humanitarian efforts: when should resources be allocated to paediatric heart surgery? Cardiol Young 2019;29:36-9.

14. Sanders GD, Maciejewski ML, Basu A. Overview of Costeffectiveness Analysis. JAMA 2019;321:1400-1.

15. Russo CA, Elixhauser A. Hospitalizations for birth defects, 2004. Healthcare Cost and Utilization Project Statistical

Brief. Available online: https://www.ncbi.nlm.nih.gov/ books/NBK63495/

16. Raj M, Paul M, Sudhakar A, et al. Micro-economic impact of congenital heart surgery: results of a prospective study from a limited-resource setting. PLoS One 2015;10:e0131348.

17. Ferket BS, Oxman JM, Iribarne A, et al. Cost-effectiveness analysis in cardiac surgery: A review of its concepts and methodologies. J Thorac Cardiovasc Surg 2018;155:167181.e11.

18. Cardarelli M, Vaikunth S, Mills K, et al. Cost-effectiveness of Humanitarian Pediatric Cardiac Surgery Programs in Low- and Middle-Income Countries. JAMA Netw Open 2018;1:e184707. 